\title{
A agenda agrícola no sistema multilateral do comércio em perspectiva histórica*
}

\author{
Ivan Tiago Machado Oliveira'
}

\section{Resumo}

O trabalho traça uma análise histórica das negociações sobre agricultura no sistema multilateral de comércio desde o GATT/1947 até a presente rodada da OMC numa perspectiva brasileira. A partir de uma perspectiva analítico evolutiva, e com base fundamentalmente em referencial brasileiro, faz-se uma apresentação do contexto internacional no qual o sistema multilateral foi gerado e identificam-se as interações entre ele e a não inserção da temática agrícola dentro das regras multilaterais no pós-Segunda Guerra. Ademais, uma análise das lógicas de conflitos e negociação entre os países em desenvolvimento e aqueles desenvolvidos é apresentada no sentido de se observar a interação entre o comércio internacional agrícola e o desenvolvimento econômico. Por fim, são feitas considerações sobre a atual rodada de negociações multilaterais, a Rodada Doha, e a sua relevância na ótica dos países em desenvolvimento, tomando-se em conta as negociações agrícolas, as quais são o centro do processo negociador multilateral.

Palavras-chave: Comércio internacional. Agricultura. Desenvolvimento. OMC. Brasil.

\section{Introdução}

Início do século XXI. Transformações importantes vêm acontecendo no mundo econômico e apresentando consequências nada desprezíveis para o progresso econômico das nações. Um velho e ruidoso debate sobre a ligação entre comércio internacional e desenvolvimento parece tomar contornos mais consensuais,

\footnotetext{
* Recebido em 17.08.2009

Aprovado em 14.01.2010

1 Economista, Doutorando em Administração pelo NPGA/UFBA e Pesquisador do Instituto de Pesquisa Econômica Aplicada (IPEA). Os argumentos contidos no presente trabalho representam exclusivamente opiniões do autor. e-mail: ivan.oliveira@ipea.gov.br
} 
pelo menos num plano mais geral e de longo prazo. A interdependência econômica crescente, decorrente do incremento dos fluxos comerciais e de investimentos pelo mundo afora, trouxe consigo um olhar menos negativo, principalmente nos países menos avançados, acerca das possibilidades das trocas internacionais servirem como um elemento capital de fomento ao desenvolvimento econômico das nações.

O SMC chega ao século XXI com uma nova roupagem, mais institucionalizada e efetiva na condução da regulação internacional do comércio. A OMC tornou-se uma instituição central enquanto componente de suporte à atual onda de globalização. Ademais, neste início de século, a luta pelo desenvolvimento das regiões mais pobres do planeta também passou a ecoar de forma mais relevante nas instituições internacionais como a OMC. Observa-se certa volta às demandas dos países mais pobres colocadas em meados no século passado, quando das negociações acerca da Carta de Havana que criava a OIC. Conceito-chave que norteou as ações do mundo econômico nos mais diversos países durante boa parte da segunda metade do século XX, estando marginalizado nas últimas décadas pelas crises que assolaram o mundo, o desenvolvimento volta à cena internacional no início de século XXI.

É nesse contexto que os membros da OMC lançam a atual rodada de negociações comerciais multilaterais, a Rodada Doha. A retórica desenvolvimentista em prol dos países menos avançados foi a base de lançamento da Rodada, apontando para o tema agrícola como pilar fundamental das negociações. Não obstante a liberalização do comércio agrícola seja considerada como elemento central da Rodada, novas negociações acerca de diversos outros temas tais como: serviços, produtos não agrícolas, propriedade intelectual, investimentos, comércio eletrônico etc., foram também lançadas em Doha, buscando uma óbvia harmonização de interesses entre os países em desenvolvimento e os países desenvolvidos.

A importância dada aos interesses dos países em desenvolvimento na atual rodada de negociações da OMC, pelo menos retoricamente, pode ser vislumbrada de forma clara no seguinte excerto da Declaração Ministerial de Doha: 
We recognize the need for all our peoples to benefit from the increased opportunities and welfare gains that the multilateral trading system generates. The majority of WTO members are developing countries. We seek to place their needs and interests at the heart of the Work Programme adopted in this Declaration. Recalling the Preamble to the Marrakesh Agreement, we shall continue to make positive efforts designed to ensure that developing countries, and especially the least-developed among them, secure a share in the growth of world trade commensurate with the needs of their economic development. In this context, enhanced market access, balanced rules, and well targeted, sustainably financed technical assistance and capacity-building programmes have important roles to play. ${ }^{2}$ (MINISTERIAL..., 2001).

Desde a quarta Conferência Ministerial da OMC, em Doha, quando o mandato negociador sobre os variados temas foi acordado, as negociações tomaram corpo de forma permanente em Genebra, tendo ocorrido eventos posteriores que buscaram diminuir as divergências entre posicionamentos dos países relativamente aos temas negociados. Num primeiro momento, pode-se citar a quinta Conferência Ministerial, ocorrida em Cancun em setembro de 2003, fracassada pela falta de entendimento entre os países em desenvolvimento e seus pares desenvolvidos sobre a liberalização agrícola e ditos temas de Cingapura. Vale ressaltar que, do ponto de vista dos interesses brasileiros na Rodada (focados no tema agrícola), a Conferência em Cancun trouxe à tona a participação do G-20 como interlocutor importante nas negociações. ${ }^{3}$

2 O comércio internacional pode desempenhar um papel importante na promoção do desenvolvimento econômico e na redução da pobreza. Nós reconhecemos a necessidade de todos os nossos povos de beneficiar do aumento das oportunidades e de ganhos de bem-estar que o sistema multilateral de comércio gera. A maioria dos membros da OMC são países em desenvolvimento. Buscamos colocar suas necessidades e seus interesses no centro do Programa de Trabalho adotado na presente Declaração. Recordando o Preâmbulo do Acordo de Marraqueche, iremos continuar a fazer esforços positivos concebidos para assegurar que os países em desenvolvimento, e especialmente dos menos desenvolvidos entre eles, tenham garantida uma quota no crescimento do comércio mundial proporcional às necessidades do seu desenvolvimento econômico. Neste contexto, um melhor acesso aos mercados, regras equilibradas, e bem orientadas, assistência técnica sustentavelmente financiada e programas de capacitação têm papéis importantes a desempenhar. (Tradução livre).

3 O G-20, grupo de países em desenvolvimento liderados pelo Brasil e pela Índia com atuação concentrada nas negociações agrícolas, passou, desde então, a ter voz ativa e importância substancial para o prosseguimento da Rodada Doha. 
As negociações comerciais multilaterais ficaram relativamente estagnadas até meados de julho de 2004, quando se conseguiu chegar a um acordo para a retomada efetiva das negociações (The July 2004 package). As negociações prosseguiram por um ano e meio até a sexta Conferência Ministerial da OMC, realizada em Hong Kong em dezembro de 2005. Nesse encontro, algumas arestas foram aparadas em relação aos temas mais controversos e um progresso relativo foi obtido em áreas específicas, como em relação aos subsídios à exportação agrícola, que devem ser extintos completamente até 2013. Entrementes, muito ainda resta de controverso e não acordado acerca de temas muito importantes para a Rodada, como aqueles relacionados à agricultura (acesso a mercado e apoio interno), serviços e bens não agrícolas. Entre avanços e recuos, as negociações no âmbito da OMC ainda não tiveram resultado efetivo que seja consubstanciado num acordo final para a Rodada Doha.

Feita essa breve introdução aos acontecimentos relacionados ao mandato negociador da Rodada Doha, iremos iniciar, a seguir, uma exploração mais particularizada acerca da regulação do comércio agrícola no SMC. Primeiramente, apresentaremos uma análise histórico-evolutiva das negociações sobre agricultura no SMC, desde o GATT 1947 até a Rodada Uruguai, quando foi criado o Acordo sobre Agricultura (AsA). Ademais, as negociações agrícolas na Rodada Doha serão analisadas detalhadamente, observando-se os principais pontos discutidos nos pilares da negociação numa perspectiva brasileira. Por se tratar de um tema "vivo", dinâmico, um work in progress, apresentaremos os principais resultados das negociações até julho de 2008, além de algumas perspectivas sobre o seu futuro.

\section{Da carta de Havana ao acordo sobre agricultura: o tema agrícola no sistema multilateral de comércio}

Desde o período anterior ao fim da Segunda Guerra, quando da assinatura, em 1941, da Carta do Atlântico, os EUA e o Reino Unido já sinalizavam para a construção de uma nova ordem econômica internacional, na qual o ideal liberal estaria como elemento de suporte às relações entre as nações. Diante de tais ideias, a liberalização comercial era vista como um mecanismo útil e necessário ao 
progresso econômico internacional, incluindo aí o comércio de matérias primas, produtos agrícolas.

Mesmo alguns anos mais tarde, os EUA continuavam a defender uma liberalização comercial ampla, com remoção de barreiras tanto tarifárias quanto quantitativas ao comércio internacional como meio de gerar desenvolvimento e ajudar na conformação de um novo sistema mundial. Contudo, com mudanças no ambiente político internacional e também nas pressões internas por proteção, ocorridos nos anos seguintes, os EUA modificam sua atuação na organização do sistema comercial internacional que emergia, adotando posicionamentos utilitaristas com teor protecionista. Observa-se, assim que:

Although the United States took the position, in its negotiations with Britain preceding the Havana Conference, that countries should remove all quantitative restrictions, the U.S. Agriculture Department wanted agriculture sector to be excluded. ${ }^{4}$ (KHOR, 2001, p.29).

Com a criação do GATT, em 1947, mecanismos de ordem jurídica internacional para tratar do comércio de bens, de maneira geral, inclusive do comércio agrícola, foram forjados. Entretanto, diversos dispositivos do GATT davam tratamento diferenciado aos produtos agrícolas, denotando a complexidade e sensibilidade do tema agrícola nas negociações comerciais internacionais. Com tais exceções às regras multilaterais, abria-se a possibilidade dos países instituírem medidas protecionistas relativamente aos produtos agrícolas, seja por meio de barreiras tarifárias, não tarifárias (como quotas e outras restrições quantitativas) ou de subsídios à produção doméstica e à exportação desses produtos.

No que concerne às restrições quantitativas, o Artigo XI do GATT 1947 deixava claro que era proibida a utilização de quotas e outras formas de restrição sobre quantidades comercializadas, trazendo, contudo, algumas exceções ligadas à produção agrícola, como: 1) restrições à exportação relacionadas à prevenção ou

\footnotetext{
4 "Embora os Estados Unidos assumissem a posição, em suas negociações com a Grã-Bretanha que antecederam a Conferência de Havana, de que os países deveriam eliminar todas as restrições quantitativas, o Departamento de Agricultura dos Estados Unidos quis que o sector agrícola fosse excluído." (tradução nossa).
} 
alívio de escassez de alimentos nas economias exportadoras; 2) restrições à importação e exportação, quando necessárias à aplicação de regulamentos ou padrões para a graduação, classificação e comercialização de commodities no cenário internacional; e 3) restrições à importação, tendo por fim a viabilização de restrição da produção e/ou comercialização de determinado produto nacional similar ou a remoção de excesso temporário da produção doméstica similar.

Não havia, inicialmente, no GATT 1947, qualquer proibição relacionada ao uso de medidas de apoio (subsídios) tanto no âmbito doméstico quanto àqueles ligados às exportações. Todavia, em 1955, ficou acordada a proibição dos subsídios à exportação pelas regras do GATT (Artigo XVI: 4) com a anuência de, mais uma vez, deixar de lado a categoria produtos primários, na qual estão inseridos os produtos agrícolas, conformando um verdadeiro tratamento especial e diferenciado às avessas no comércio internacional que marcaria o SMC durante mais de quarenta anos. Assim sendo, como colocado por Jank e Thorstensen (2005, p. 38), “As exceções relacionadas aos subsídios e às restrições quantitativas foram suficientes para deixar a agricultura à margem da regulamentação do GATT 1947.”

Vale frisar que, no pós-Segunda Guerra, ainda vigorava nos EUA o Agriculture Adjustment Act de 1938, por meio do qual ficava permitido o uso de tarifas, restrições quantitativas e subsídios às exportação como mecanismos de proteção e fomento à produção agrícola, atendendo aos interesses dos fortes lobbies ruralistas no Congresso dos EUA. Destarte, mesmo com a arquitetura do sistema comercial ao estilo tailor-made, os EUA, não satisfeitos, utilizaram-se da Seção 22 da referida Lei Agrícola para impor quotas sobre a importação de algodão, trigo, amendoim, aveia, centeio, cevada e todos os derivados de tais produtos, além dos produtos lácteos.

Observa-se que o uso de tais medidas protecionistas de ordem quantitativa usadas pelos EUA sobre diversos produtos agrícolas não estavam de acordo com as exceções apresentadas dentro das regras do GATT 1947, significando, dessa forma, um claro descumprimento delas. Entretanto, em 1955, os EUA obtiveram um waiver (suspensão de obrigações) no GATT, relacionado às restrições quantitativas sobre produtos agrícolas, podendo, a partir de então, adotar tais medidas sem a observância dos requisitos necessários existentes no regramento gattiano. 
Ademais, muitos países da Europa que vinham fazendo uso dos mecanismos legais de proteção fundamentados no argumento de problemas no balanço de pagamentos, aproveitando da brecha aberta no sistema pelos EUA, conseguiram também a suspensão de obrigações relativas à agricultura. Fica, assim, patente que o waiver dado aos EUA significou a exclusão efetiva do tema agrícola das negociações multilaterais de comércio que buscavam a redução dos gravames às trocas entre as nações, denotando o poder que os EUA detinham na liderança do processo e a importância de que seus interesses fossem minimamente atendidos como forma de manutenção "tranquila" e "legítima" do SMC.

De alguma forma, o waiver concedido aos EUA no GATT levou, e até mesmo encorajou a Europa Comunitária a lançar a Política Agrícola Comum (PAC) como um elemento essencial do Tratado de Roma de 1957, observando-se, pois, a concordância tácita da maior potência mundial da época aos mecanismos de proteção europeus, tanto por motivos geopolíticos quanto por confluências de ideias protetoras sobre o setor agrícola ${ }^{5}$.

A marginalização do debate sobre o tema agrícola nas negociações multilaterais pode ser vislumbrada mediante a observação de que ele receberá, até a Rodada Uruguai (1986-1994), um tratamento meramente retórico, quanto existente. Na Rodada Tóquio (1973-1979), por exemplo, falou-se em negociações sobre agricultura, atendendo a pressões dos países em desenvolvimento. Contudo, não se conseguiu chegar a um resultado nas negociações sobre agricultura, como era de se esperar acerca de um tema tão sensível aos interesses das potências econômicas mundiais numa época marcada pela ascensão protecionista renovada em diversos setores da economia, inclusive o agrícola.

É fato, portanto, que a falta de regulamentação internacional sobre o comércio agrícola abria espaço para o uso arbitral de subsídios e proteção fronteiriça aos produtos agrícolas pelos países, principalmente os desenvolvidos, que tinham recursos suficientes para tal. Ademais, Jank e Thorstensen (2005, p. 39) lembram

5 Para uma análise aprofundada sobre a constituição, evolução e reformas da Política Agrícola Comum (PAC) da Comunidade Europeia, ver Carisio (2004). 
bem que: "Como essas proteções acabavam por ocasionar um excesso de oferta, este somente era comercializado no mercado internacional por meio da utilização de elevados subsídios à exportação, o que acarretava instabilidade nos preços mundiais". A instabilidade nos preços agrícola mundiais, resultante da exportação subsidiada dos países desenvolvidos, afetava (e ainda hoje afeta) diretamente muitos dos países em desenvolvimento que estavam fazendo esforços para se industrializarem e dependiam, num primeiro momento, das exportações de produtos agrícolas como geradoras de divisas necessárias à importação de bens de capital.

Com o debate multilateral sobre produtos agrícolas dominado pelos interesses das grandes potências, qualquer iniciativa que buscasse a inserção do tema agrícola de forma efetiva no SMC estava à mercê de tais interesses. Somente na Rodada Uruguai (1986-1994) as potências econômicas agro-protecionistas se mostraram minimamente concordantes com o lançamento de negociações para a criação de regras sólidas para o tema agrícola no SMC. Por um lado, os EUA, tendo em mente a possibilidade de aumentar suas exportações agrícolas para o velho mundo e assim amenizar seu problema nas contas externas, sustentaram uma posição mais agressiva em relação à agricultura na Rodada Uruguai. Por outro lado, os europeus, adotando posicionamento fundamentalmente defensivo em relação ao tema agrícola, buscavam manter firmemente sua política de proteção e subsídios agrícolas. Logo, a Comunidade Europeia barganhava com os norte-americanos algum acesso ao seu mercado em troca de um compromisso americano em não questionar a PAC no GATT.

Foi justamente a partir do entendimento entre os negociadores dos EUA e da Europa, com o Blair House Accord de 1992, que saíram as principais diretrizes que viriam a desbloquear as negociações da Rodada Uruguai e nortear a construção de um acordo final sobre o comércio agrícola, culminando na assinatura do Acordo sobre Agricultura (AsA), incorporado ao GATT 1994 ao fim da Rodada ${ }^{6}$.

${ }^{6}$ Cabe ressaltar que foi ainda estabelecido, na Rodada Uruguai, o Acordo sobre Aplicação de Medidas Sanitárias e Fitossanitárias (SPS, na sigla em inglês), que busca disciplinar a regulamentação relativa à segurança dos alimentos e à sanidade vegetal e animal. Ademais, pode-se dizer que a criação do Acordo sobre SPS representa um ganho a partir dos esforços do Grupo de Cairns no sentido de se obterem regras claras e específicas acerca da imposição de medidas que possam acabar por se transformar em barreiras ao comércio agrícola. 
Através do Acordo sobre Agricultura, o SMC finalmente trouxe regras mais claras e efetivas em relação ao comércio agrícola. Dentre as novidades na regulação do setor, pode-se observar: 1) consolidação e corte posterior dos subsídios tanto à produção doméstica quanto à exportação de produtos agrícolas; 2) garantia de acesso tanto corrente quanto mínimo para produtos agrícolas que tinham seu comércio dificultado pelos altos níveis de proteção; 3) a tarificação que consiste na transformação de barreiras não tarifárias em tarifas; e 4) a consolidação e diminuição média das tarifas.

Cabe lembrar que os três pilares da negociação agrícola (subsídios à exportação, apoio interno e acesso a mercado) receberam definições precisas com o AsA. No primeiro pilar, os compromissos específicos acordados estão relacionados à competição das exportações, incluindo aí subsídios diretos a produtos agrícolas voltados à exportação ${ }^{7}$. Com o AsA, compromissos de diminuição de tais subsídios foram estabelecidos da seguinte forma: a) redução da quantidade exportada subsidiada de $21 \%$, para os países desenvolvidos, e de $14 \%$, para os países em desenvolvimento, segundo os valores de referência do período base 1986-1990; b) diminuição no nível total de gastos orçamentários ligados aos subsídios à exportação do setor agrícola em 36\%, para os países desenvolvidos, e em 14\% para os países em desenvolvimento. Ademais, ficou estabelecido um período de implementação de tal esquema de redução dos subsídios à exportação relacionados à agricultura em seis e dez anos para os países desenvolvidos e em desenvolvimento, respectivamente. ${ }^{8}$

O segundo pilar das negociações é aquele relacionado aos subsídios domésticos à agricultura (também chamado de apoio interno), referindo-se assim ao auxílio e proteção que os governos dão aos produtores nacionais de produtos agrícolas, seja por meio de mecanismos de subsídio ao preço de mercado ou de transferências diretas aos produtores. Para classificar os diferentes tipos de subsídios agrícolas domésticos, foram criadas três caixas, agrupamentos segundo critérios de distorção de comércio. São elas: caixa amarela, caixa azul e caixa verde.

\footnotetext{
7 Vale frisar que esse tipo de subsídio é proibido pelo regramento da OMC através do Acordo sobre Subsídios e Medidas Compensatórias. No entanto, o AsA veio abrir uma exceção à sua utilização para o setor agrícola.

8 É importante colocar que os créditos à exportação e outras medidas equivalentes não foram objeto de qualquer compromisso no AsA.
} 
A caixa amarela compreende as políticas de apoio interno capazes de distorcer o comércio agrícola internacional. Tais políticas são compostas por pagamentos diretos aos produtores e sistemas de sustentação de preço de mercado, estando sujeitas a limitações quanto ao seu uso durante determinado período de tempo, bem como a acordos de diminuição. Os membros da OMC que não acordaram em reduzir os mecanismos da caixa amarela não estão, em princípio, autorizados a adotá-los.

Já a caixa azul abrange as formas de apoio interno capazes de distorcer o comércio internacional, sendo, entretanto, livres de acordos multilaterais por se relacionarem a programas de limitação da produção agrícola. Destarte, o apoio observado na caixa azul deve ser considerado como uma exceção aos subsídios domésticos relacionados com a produção, os quais são classificados na caixa amarela. Tal aspecto se deve à necessidade dos subsídios internos na caixa azul de atender ao requisito de ser uma medida governamental de limitação da produção interna, independentemente de ser considerado um pagamento direto aos agricultores ${ }^{9}$.

Na caixa verde, as medidas de apoio interno que não distorcem, ou distorcem minimamente, o comércio agrícola são classificadas. Não existe nenhum compromisso de redução acordado sobre as medidas enquadradas na caixa verde, contudo, as mesmas não podem estar atreladas a nenhum tipo de garantia de preços aos produtores. Dentre tais medidas, podem-se citar: as assistências a desastres, pagamento direto ao produtor desvinculado da produção, programas governamentais de pesquisa, controle de pestes e doenças, extensão rural e infraestrutura.

Vale acrescentar que existe ainda uma cláusula chamada "de minimis" que versa sobre a autorização de continuação de políticas preferenciais, de subsídios e de dumping (tanto em relação um produto específico quanto de forma não especificada), desde que as mesmas não excedam certo valor máximo, nível “de minimis", avaliado como limite imprescindível para a manutenção da concorrência. O

9 Os pagamentos diretos atrelados à limitação da produção, enquadrados na caixa azul, foram forjados fundamentalmente para acomodar os subsídios previstos na Reforma MacSharry da PAC em 1992. Para maiores informações sobre as reformas da PAC, ver Carisio (2004). 
nível "de minimis" para os países desenvolvidos enquadrados nessa cláusula foi estabelecido em até $5 \%$ do valor da produção, sendo de até $10 \%$ para os países em desenvolvimento.

Ademais, é importante lembrar que os subsídios domésticos avaliados como mais distorcivos ao comércio agrícola (caixa amarela) e, portanto, acionáveis pela via legal da OMC, são quantificados por meio da Medida Agregada de Apoio, ou Aggregate Measurement of Support (AMS). A AMS é composta por diversos elementos, como o market price support, que é caracterizado pela diferença entre o preço administrado garantido pelo governo e o preço externo de referência (preço unitário praticado no período entre 1986 e 1988), multiplicado pela quantidade da produção que pode receber o preço administrado de cada commodity, além de alguns pagamentos diretos dependentes da diferença de preços. A AMS compreende tanto os subsídios a produtos específicos quanto aqueles relacionados a toda a produção de determinado país membro. A AMS é utilizada como parâmetro nas notificações, análises e negociações comerciais do setor agrícola na OMC.

Ao fim da Rodada Uruguai, com o AsA, ficou acordado um cronograma de redução dos subsídios domésticos que distorcem o comércio internacional agrícola no qual era previsto uma diminuição de $20 \%$ da AMS total nos países mais avançados no período que iria de 1995 a 2000. Para os países em desenvolvimento, tal redução deveria ocorrer em 13,3\% no período que se estendia de 1995 a $2004 .{ }^{10}$ No entanto, cabe frisar que diversos tipos de subsídios domésticos ficaram de fora dos compromissos de redução acordados na Rodada Uruguai, dentre os quais vale citar: a) aqueles relacionados à chamada caixa $S \hookleftarrow D$, em que um tratamento especial e diferenciado aos países em desenvolvimento é oferecido relativamente às medidas de assistência governamental destinadas a programas para o desenvolvimento de atividades rurais e agrícolas; b) os enquadrados na cláusula "de minimis" de suporte tanto a produto específico quanto não específico; c) os subsídios da caixa azul; e d) os da caixa verde.

${ }^{10}$ Todos os países-membros que não possuem compromissos acordados de redução da AMS devem manter seu AMS dentro dos limites “de minimis”, isto é, até 5\% do valor da produção para países desenvolvidos e $10 \%$ para países em desenvolvimento. 
O terceiro pilar das negociações agrícolas é focado na questão do acesso a mercado, que se refere ao grau de abertura de determinada economia aos produtos importados. No que concerne ao acesso corrente, ficou acordado que os países manteriam os níveis de importação dos produtos agrícolas de acordo com o volume de importação anual médio observado no período base 1986-88. Já em relação ao acesso mínimo, acordou-se na OMC que seus membros permitiriam o acesso de produtos importados aos seus mercados num patamar correspondente a $3 \%$ do consumo doméstico observado entre 1986 e 1988. Além disso, o acesso mínimo deveria ser incrementado para 5\% do consumo do período base até 2000, para os países desenvolvidos, e até 2004para os em desenvolvimento. O cumprimento do acesso mínimo é realizado por meio de quotas tarifárias, sendo definida uma tarifa intraquota mais baixa e outra, extraquota, mais elevada.

A tarificação foi acordada como regra geral no AsA no pilar de acesso a mercado. Assim, as barreiras não tarifárias deveriam ser eliminadas e, em seu lugar, ser estabelecidos equivalentes tarifários, os quais comporiam o nível base tarifário do país membro juntamente com as tarifas normais. $\mathrm{O}$ nível base resultante da tarificação deveria ser cortado em 36\%, para os países desenvolvidos e em $24 \%$ para aqueles em desenvolvimento, em um período de seis e dez anos, respectivamente, a partir de 1995. Ademais, um patamar mínimo de acesso a mercado ficou estabelecido no caso de um país-membro não vir a converter suas barreiras não tarifárias em tarifas equivalentes. Tal acesso mínimo especial deverá ser $4 \%$ do consumo anual médio relativamente ao período base de 1986-1988, devendo ocorrer uma ampliação de $0,8 \%$ no consumo relativo ao período base até o final de 2000, para os desenvolvidos. No que tange aos países em desenvolvimento, deverá haver um acesso mínimo especial em relação a $1 \%$ do consumo anual médio do período base, aumentando de maneira uniforme para 2\% em 1999 e 4\% em 2004. $\mathrm{O}$ acesso mínimo especial segue os padrões de efetivação do acesso mínimo geral, utilizando-se, assim, de quotas tarifárias para sua implementação.

Um aspecto que não pode deixar de ser analisado em relação ao processo de tarificação é que o mesmo acabou por gerar picos e escaladas tarifárias. Nesse contexto, veio a ocorrer a consolidação, pelos membros da OMC, de tarifas equivalentes muito elevadas, o que acabou por impossibilitar o comércio de uma gama 
diversa de produtos agrícolas, dando margem aos interesses protecionistas tanto das grandes potências quanto de tantos outros países desenvolvidos e em desenvolvimento. Não bastasse tal fato, esses interesses foram ainda acomodados por meio da Special Safaguard Provision (SSP) para produtos agrícolas. Com a SSP, os países membros ganham o direito de impor tarifas adicionais sobre produtos agrícolas importados no intuito de salvaguardar os produtores nacionais da concorrência internacional ${ }^{11}$.

Destarte, a SSP trouxe consigo a possibilidade dos países fazerem uso de proteção tarifária ao setor agrícola sem demonstrar ameaça ou efetivo dano para a produção nacional, isto é, sem comprovar a possibilidade real de que os produtores domésticos possam sofrer efeitos adversos advindos de uma maior exposição internacional. As condições para a implementação da SSP pelos países-membros são as que seguem: 1) obrigatoriedade de inscrição do símbolo SSG (special safaguard) relativamente ao produto na lista de o compromisso do país que deseja tomar a medida; 2) necessidade de que tenha sido realizada a tarificação em relação ao produto em questão; e 3) ativação do gatilho, seja por um aumento importante das importações do produto, superando certo volume pré-estabelecido, ou por importação abaixo do preço de referência.

É de grande relevância notar que o Artigo XIII do AsA contém a famosa Cláusula de Paz, instrumento que denotou os interesses das grandes potências no acordo agrícola da Rodada Uruguai a partir do Blair House Accord, por meio da qual os membros do SMC ficaram impedidos de acionar os subsídios agrícolas no Órgão de Solução de Controvérsias da OMC e também de fazer uso de qualquer medida de compensação durante um período de nove anos, que foi de 1995 a 2003.

Como se pode perceber com clareza, mesmo com a introdução do tema agrícola no SMC, dando-lhe regras mais sólidas e eficazes, continuaram a existir diversas cláusulas de escape, que vieram a atender principalmente aos interesses agrícolas protecionistas das potências econômicas mundiais (EUA, UE e Japão).

${ }^{11}$ Os produtos agrícolas passaram, assim, a ser susceptíveis de aplicação de salvaguardas tanto segundo o Artigo XIX do GATT 1994 e o Acordo sobre Salvaguardas quanto pela SSP. 
Tais mecanismos de contorno da lei dentro de legalidade acabaram por tornar claro que as promessas de uma abertura efetiva e de uma diminuição importante nos níveis de apoio ao setor agrícola não viriam a ser cumpridas em sua plenitude, o que gerou um crescente descontentamento por parte de diversos países em desenvolvimento que esperavam um impulso liberalizante no comércio agrícola tão importante quanto nas demais áreas negociadas na Rodada Uruguai do GATT.

\section{O mandato negociador agrícola da rodada Doha: desafios e expectativas}

Seguindo o mandato previsto no AsA, em seu Artigo XX, as negociações que davam continuidade ao processo de diminuição da proteção e do apoio agrícola foram retomadas em 2000, um ano antes do final do período de implementação do que foi acordado na Rodada Uruguai. Tais negociações iniciaram diante de um espectro de opiniões e interesses dos mais variados possíveis entre os membros da OMC, observando-se posicionamentos maximalistas e propostas assaz genéricas sobre o tema agrícola, o que acabou por resultar num insucesso absoluto das negociações que ocorreram nos anos de 2000 e 2001.

Quando do lançamento da Rodada Doha, em novembro de 2001, existiu o consenso necessário acerca do tema agrícola enquanto cerne das negociações da rodada, devendo-se levar em conta as distorções e as promessas não cumpridas sobre a temática na OMC. Assim, o mandato negociador de Doha reafirma o objetivo de longo prazo presente no AsA, qual seja:

[...] to establish a fair and market-oriented trading system through a programme of fundamental reform encompassing strengthened rules and specific commitments on support and protection in order to correct and prevent restrictions and distortions in world agricultural markets. ${ }^{12}$ (MINISTERIAL..., 2001).

\footnotetext{
12 “[...] estabelecer um sistema comercial justo e orientado para o mercado através de um programa de reforma fundamental que inclua regras reforçadas e compromissos específicos de apoio e proteção a fim de corrigir e prevenir restrições e distorções nos mercados agrícolas mundiais." (tradução nossa).
} 
Além disso, a Declaração Ministerial de Doha reafirmou o compromisso de negociação nos três pilares do tema agrícola, garantiu o tratamento especial e diferenciado aos países em desenvolvimento e ressaltou ainda que preocupações não comerciais seriam levadas em consideração nas negociações, como claramente exposto no seguinte excerto:

[...] we commit ourselves to comprehensive negotiations aimed at: substantial improvements in market access; reductions of, with a view to phasing out, all forms of export subsidies; and substantial reductions in trade-distorting domestic support. We agree that special and differential treatment for developing countries shall be an integral part of all elements of the negotiations and shall be embodied in the schedules of concessions and commitments and as appropriate in the rules and disciplines to be negotiated, so as to be operationally effective and to enable developing countries to effectively take account of their development needs, including food security and rural development. We take note of the non-trade concerns reflected in the negotiating proposals submitted by Members and confirm that non-trade concerns will be taken into account in the negotiations as provided for in the Agreement on Agriculture. ${ }^{13}$ (MINISTERIAL..., 2001).

Para que se possa entender de forma mais acurada a dinâmica dos interesses presentes das negociações agrícolas da OMC, é importante voltar a atenção para alguns importantes acontecimentos do mundo político comercial ocorridos nos EUA e na União Europeia nos últimos anos. Em um primeiro momento, cabe observar que a União Europeia apresentou novidades em sua Política Agrícola Comum com a Reforma Fischler de 2003. Na verdade, embora alguma evolução positiva possa

\footnotetext{
${ }^{13}[\ldots]$ Nós nos comprometemos a realizar negociações amplas visando: melhorias substanciais no acesso ao mercado; reduções de, tendo em vista a eliminação gradual, todas as formas de subsídios à exportação, e reduções substanciais no apoio interno causador de distorção comercial. Concordamos que o tratamento especial e diferenciado para países em desenvolvimento deve ser parte integrante de todos os elementos das negociações, e deve ser incorporado nos modelos de concessões e de compromissos e de forma apropriada nas regras e disciplinas a negociar, de forma a ser operacionalmente eficaz e para permitir que os países em desenvolvimento tenham efetivamente em conta suas necessidades de desenvolvimento, incluindo a segurança alimentar e o desenvolvimento rural. Tomamos nota das preocupações não comerciais, refletidas nas propostas de negociação apresentadas por Membros, e confirmamos que tais preocupações serão levadas em conta nas negociações como previsto no Acordo sobre a Agricultura (tradução nossa).
} 
ser vislumbrada na última reforma da PAC, que se adequou à entrada dos novos membros, ela continuou a seguir o lema de "reformar a fachada para que o cerne não mude", persistindo, assim, importantes mecanismos de distorção do comércio agrícola como os subsídios domésticos e as exportações em somas astronômicas.

Do outro lado do Atlântico, entrava em cena a nova Lei Agrícola dos EUA, a Farm Act 2002, que vigorará até 2008. Com essa Lei, para acomodar os interesses ruralistas norte- americanos, ocorreu um aumento substancial dos subsídios agrícolas relativamente aos anos precedentes, devendo ser disponibilizado mais de US $\$ 40$ bilhões por ano para apoio ao setor agrícola dos EUA, o que significa um incremento de quase $100 \%$ relativamente ao montante disponibilizado pela Lei Agrícola de 1996. ${ }^{14}$ Ademais, a autorização dada, em 2002, pelo Congresso dos EUA ao Executivo para negociar acordos comerciais por meio da Trade Promotion Authority, com validade prorrogada até 2007, trazia consigo restrições importantes relativamente às negociações agrícolas, especialmente para aqueles produtos considerados como sensíveis. Como bem coloca Ricupero:

Efetivamente, em cerca de 350 produtos sensíveis, o Executivo terá de submeter-se a complicadas consultas, às vezes com não menos que quatro comissões parlamentares (as duas de Agricultura, a "Ways and Means", da Câmara e a de Finanças, do Senado), se quiser negociar a redução de barreiras. As consultas são minuciosas e pré-estabelecidas nos mínimos detalhes. A negociação não está proibida em tese, mas na prática não será fácil superar essa verdadeira corrida de obstáculos. Boa parte dos produtos incluídos na lista são aqueles para os quais os Estados Unidos fizeram a menor redução possível no fim da Rodada Uruguai: 15\%. (RICUPERO, 2002, p. 16-17)

Diante de tais interesses e posicionamentos claramente protecionistas das maiores economias do mundo, as negociações agrícolas da Rodada Doha prosseguiram em Genebra sem grande sucesso. Os impasses persistiram nos três pilares do

\footnotetext{
${ }^{14}$ É interessante observar que tal movimento de aumento nos subsídios agrícolas nos EUA veio em paralelo ao lançamento da Rodada Doha, denotando certo posicionamento estratégico por parte dos EUA, já observado em ocasiões anteriores, antes do início de determinadas negociações nas quais são esperadas pressões por reduções nos níveis de proteção de certos setores.
} 
tema agrícola com alguns países, como o Brasil, tendo posicionamento mais agressivo em relação à liberalização de forma mais geral e alguns outros defendendo pontos de vista protecionistas em aspectos específicos, quando não across the board.

Após o retumbante fracasso em Cancun, em fins de 2003, as negociações simplesmente estagnaram, tendo sido perdido o deadline inicialmente planejado. Contudo, é imprescindível notar que em Cancun algo novo surgiu no horizonte negociador da OMC. O G-20, criado no período imediatamente anterior à reunião, veio a tomar relevante espaço nas negociações sobre a temática agrícola na Rodada e, por conseguinte, no próprio prosseguimento da mesma de forma geral, substituindo o antigo "consenso do Quad" (EUA, UE, Canadá e Japão) por mecanismos de harmonizações sucessivas de posições de países-chave tanto desenvolvidos quanto em desenvolvimento. O grupo é marcado por uma confluência de interesses acerca das negociações agrícola, não obstante existam determinados países do G-20, como a China e a Índia, que apresentam posições claramente protecionistas relacionadas ao pilar de acesso a mercados. Esse aspecto dá ao grupo um ar esquizofrênico, o que implica maiores desafios para o líder, o Brasil, no sentido de tentar manter o G-20 unido como força importante do processo negociador e, ao mesmo tempo, não descuidar dos temas que enfrentam posicionamentos reticentes tanto das potências quanto dos "companheiros" em desenvolvimento.

Com o July 2004 Package, as negociações foram retomadas, ainda que de forma muito retardada e pouco dinâmica, resultando em compromissos tímidos que viriam a ser ratificados na Conferência Ministerial de Hong Kong, em dezembro do ano passado. Vale frisar que o propalado sucesso em Hong Kong deve ser observado de forma relativa, tendo por base que talvez o único grande feito observável derivado da reunião foi o acordo sobre o fim dos subsídios agrícolas à exportação e medidas equivalentes, algo já acordado em 2004, como será mais bem analisado a seguir.

Não obstante tenha ocorrido alguma aproximação entre as propostas dos principais grupos interessados no tema agrícola desde o início das negociações, tal tema continua a ser tanto o foco principal do mandato negociador de Doha quanto o elemento mais controverso e de complexa negociação da Rodada. Os EUA e a 
Europa Comunitária continuam bastante reticentes relativamente aos seus pontos mais sensíveis da negociação agrícola. Por um lado, a UE pressiona os norte-americanos por uma proposta mais agressiva em relação ao apoio interno. Por outro, os EUA colocam que, sem uma proposta europeia de liberalização efetiva no acesso ao seu mercado agrícola, o progresso das negociações não pode ser materializado de forma mais rápida.

O Brasil, como terceiro maior exportador agrícola do mundo e com grande potencial competitivo internacional, é um dos países de posicionamentos mais agressivos na Rodada Doha, na defesa da liberalização do comércio agrícola com redução substancial dos subsídios que o distorcem. O país vê nas negociações da Rodada Doha uma grande oportunidade, talvez a primeira em 60 anos de SMC, para o estabelecimento de regras mais justas para o comércio agrícola mundial, dando à agricultura um padrão regulatório semelhante ao observado para os produtos industriais. Ademais, o tratamento de temas sistêmicos, como os subsídios internos e às exportações, tende a tomar a frente nos interesses do país na OMC, dado que são temas de trato muito difícil em relações bilaterais.

No intuito de melhor vislumbrar o atual estágio das negociações multilaterais sobre agricultura e o seu provável devenir, vamos apresentar as recentes propostas sobre os três pilares agrícolas de forma particularizada, dando ênfase nos principais elementos que compõem o jogo de interesses em cada um deles a partir do ponto de vista brasileiro.

No pilar relacionado aos subsídios às exportações e medidas equivalentes, foram realizados os maiores avanços nas negociações agrícolas até o momento. Nesse pilar, incluem-se tanto os subsídios diretos à exportação quanto medidas equivalentes como créditos à exportação, abuso dos programas de ajuda alimentar e práticas distorcivas utilizadas por empresas estatais de comércio.

Após as negociações ocorridas durante os anos 2004 e 2005, ficou acordado em Hong Kong o fim dos subsídios às exportações até 2013. Tal data coincide com o prazo final de vencimento do orçamento da PAC e dos regimes do açúcar e lácteos da UE, como determinado pela Reforma Fischler de 2003. Assim, fica 
patente que o fim acordado dos subsídios à exportação na $\mathrm{OMC}$ veio a acomodar os interesses da UE em relação a tal temática. Por isso, não obstante a importância do tema, não se pode dar caráter de sucesso absoluto ao que ficou acordado em Hong Kong para os países em desenvolvimento, como o Brasil. Os interesses defensivos acabaram por prevalecer ${ }^{15}$. Contudo, algo de mais positivo também surgiu em Hong Kong, como relata Jank e Tachinardi (2006):

O maior ganho nas decisões sobre a eliminação dos subsídios à exportação é que haverá de forma concomitante a eliminação de medidas equivalentes, como os créditos subsidiados à exportação, as medidas de abuso da ajuda alimentar e o disciplinamento da ação das empresas estatais de comércio. (JANK; TACHINARDI, 2006, p. 7).

A importância dos interesses da UE em relação ao tema dos subsídios à exportação pode ser confirmada a partir da observação do Gráfico 1, apresentado abaixo. Levando-se em consideração o total dos subsídios à exportação, notificados à OMC entre os anos de 1995 e 2001, aqueles relacionados à UE-15 conformam $90 \%$ do total, sendo seguida pela Suíça com 5,3\% e pelos EUA e Noruega, tendo cada um $1,4 \%$ do total dos subsídios notificados.

Gráfico 1: Percentual do total de subsídios às exportações agrícolas notificados à OMC (1995-2001).

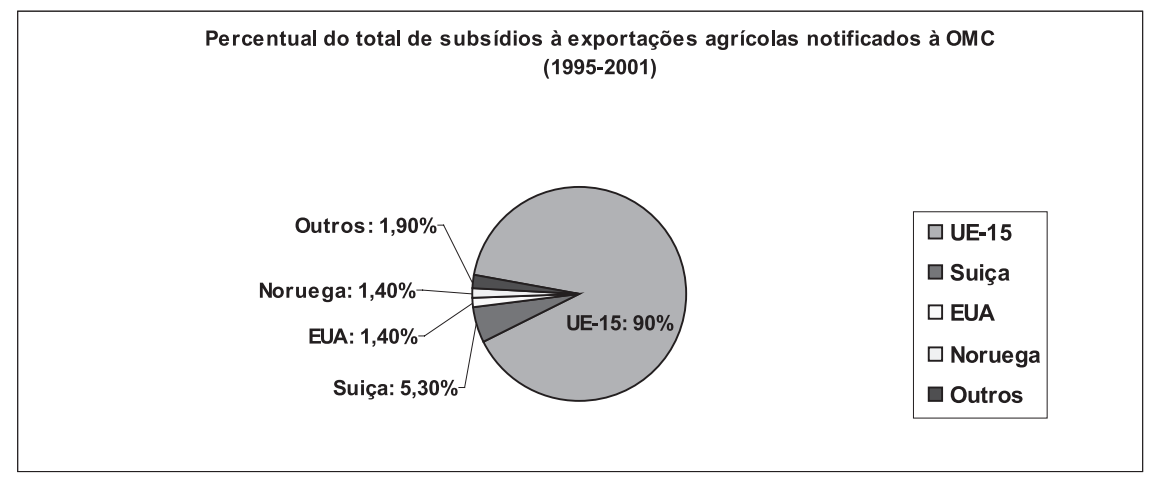

Fonte: OMC (2005).

${ }^{15}$ Vale lembrar que o G-20 defendia o ano de 2010 como ano-limite para o fim dos subsídios às exportações agrícolas. 
As perspectivas pouco animadoras para os interesses dos países do G-20, além de se fundarem do atendimento das necessidades de prazos dos principais países que fazem uso dos subsídios à exportação, também encontram eco nas estatísticas apresentadas no Quadro 1, a seguir.

Quadro 1: Subsídios às exportações agrícolas: valores notificados e utilizados em 2000, em US\$ milhões.

\begin{tabular}{|c|c|c|c|}
\hline Região & Valor Notificado (VN) & Valor Utilizado (VU) & VU/VN (\%) \\
\hline UE-15 & 2.520 & 935 & $37,1 \%$ \\
\hline Suíça & 190 & 137 & $72,1 \%$ \\
\hline Novos da UE & 80 & 26 & $32,2 \%$ \\
\hline Noruega & 40 & 32 & $79,7 \%$ \\
\hline EUA & 20 & 0,52 & $2,6 \%$ \\
\hline
\end{tabular}

Fonte: OMC (2005).

Como se pode ver, os valores dos subsídios consolidados na OMC pelos diversos países-membros estão substancialmente acima daqueles que são efetivamente usados pelos mesmos. A UE-15, por exemplo, havia consolidado na OMC, em 2000, cerca de US\$2,5 bilhões em subsídios às exportações do setor agrícola. Contudo, só utilizou cerca de 37\%, ou seja, US\$ 935 milhões. Já os EUA, que haviam notificado à OMC cerca de US\$ 20 milhões em subsídios à exportação em 2000, fizeram uso de apenas 2,6\% do total, perfazendo um valor absoluto de US\$520 mil.

O que tais estatísticas querem dizer? Elas relatam de forma clara que os países que mais subsidiam suas exportações agrícolas já vinham reduzindo o uso efetivo de tais medidas de apoio, o que não deixa de ser algo positivo. Entrementes, como os cortes nos subsídios negociados na OMC são realizados nos valores notificados à Organização, isso significa que o acordo para a redução e extinção dos subsídios à exportação na Rodada Doha virá muito mais a cortar a "água" dos subsídios, num curto prazo, do que reduzir de forma efetiva as distorções atuais. Logicamente, caso se chegue a 2013 com a extinção total de tais subsídios e medidas equivalentes, ter-se-á um resultado relativamente positivo, dando, todavia, uma margem muito grande de flexibilidade e adaptação ao principal usuário de tais mecanismos, que é a União Europeia. Ademais, o montante absoluto dos subsídios agrícolas em todo o mundo é relativamente pequeno, cerca de US\$ 3 bilhões 
(US\$ 5 bilhões se forem levadas em conta as medidas equivalentes), se comparado aos US\$ 108 bilhões notificados à OMC como apoio interno distorcivo (AMS + caixa azul + de minimis) em 2001.

Ainda sobre o pilar dos subsídios à exportação, as negociações foram focadas em alguns aspectos mais específicos relacionados às medidas equivalentes, como os créditos à exportação. Para o Brasil, o tema de maior importância talvez seja a diminuição ao máximo dos créditos às exportações para 180 dias, porquanto este é um mecanismo vastamente usado pelos EUA em sua produção agrícola exportada.

No segundo pilar das negociações, o do apoio doméstico agrícola, as coisas não se apresentam tão bem-desenvolvidas e estruturadas em direção a um acordo final sem maiores empecilhos. Em Hong Kong, o avanço foi muito tímido em relação a esse pilar, com aprovação de um texto ambíguo no qual se falou em cortes "efetivos" dos subsídios domésticos sem esclarecer, contudo, se isso aconteceria em caixas específicas ou também no nível global de cortes. Podem-se destacar dois pontos especiais em que algo novo e positivo foi criado, quais sejam: a criação de bandas para cortes diferenciados no apoio interno e a indicação da composição de tais bandas.

Em relação à estrutura da fórmula de diminuição do apoio interno, foram definidas três bandas para cortes em AMS (os subsídios da caixa amarela) e apoio total distorcivo. Ademais, indicou-se que tais bandas seriam compostas da maneira que segue: na banda mais alta, na qual os compromissos de cortes serão mais expressivos, está a UE; numa segunda banda, com cortes importantes, mas, menores que os da primeira, ficam os EUA e o Japão; e numa terceira banda, os demais países-membros tanto desenvolvidos quanto em desenvolvimento, sendo que os primeiros, com nível de AMS mais elevado,, deverão realizar um maior esforço no corte do que os demais integrantes da terceira banda.

Como se vê no Gráfico 2, a seguir, a UE-15, principal usuária das medidas de apoio interno agrícola, reduziu seus gastos com tais subsídios entre os anos de 1995 e 2000. Observando-se o nível global dos subsídios domésticos com poder de distorção do comércio agrícola (AMS + caixa azul + de minimis), vê-se que a UE15 reduziu em 36\%, de US\$ 95 bilhões para US\$ 60,8 bilhões, o valor absoluto dos 
subsídios mais distorcivos ao comércio entre os anos de 1995 e 2000. Por seu turno, o Japão diminuiu em $80 \%$ o uso de tais subsídios no mesmo período, passando de US \$ 36,8 bilhões para o patamar de US\$ 7,3 bilhões. Já os EUA aumentaram em $64 \%$, de US\$ 14,7 bilhões para US\$ 24,1 bilhões, a utilização dos subsídios mais distorcivos no período em questão, denotando a crescente pressão por medidas de apoio doméstico por parte dos ruralistas norte-americanos, algo que veio a ser ratificado e ampliado com a Farm Act de 2002, quando o montante disponível para subsidiar a produção agrícola doméstica aumentou de forma substancial.

Gráfico 2: Apoio interno agrícola notificado à OMC pelo Japão, EUA e UE-15 (1995/2000).

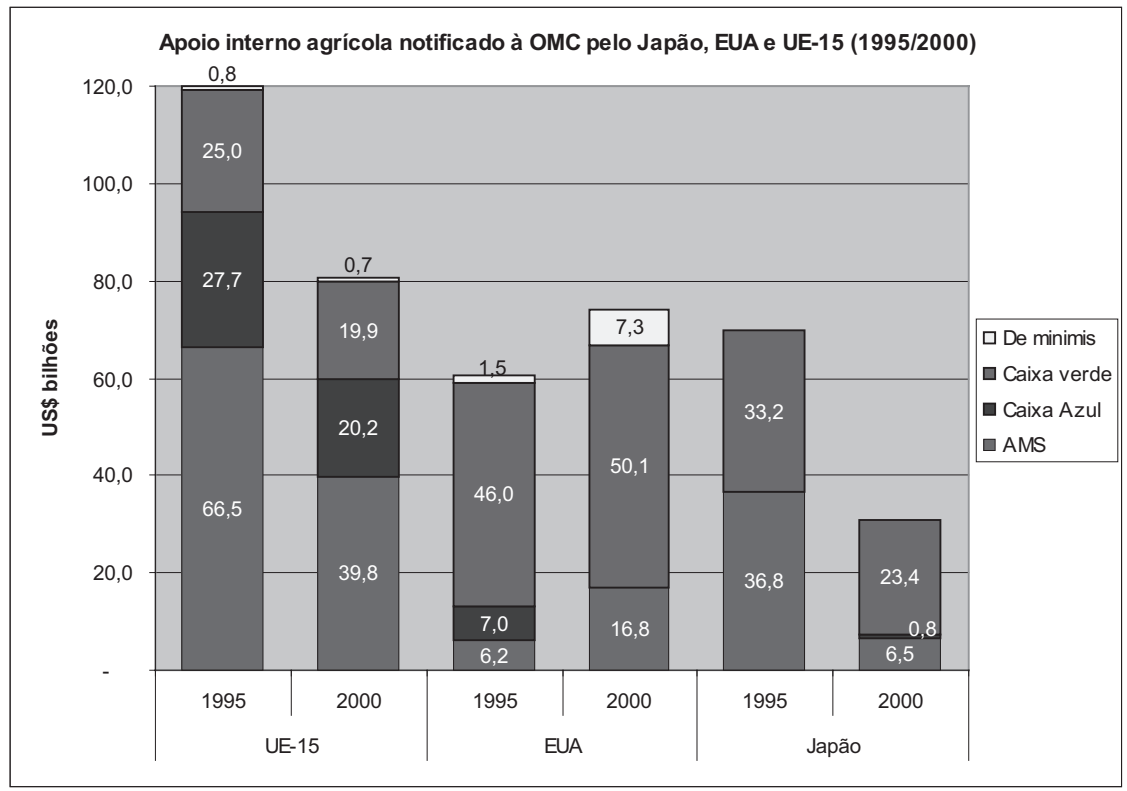

Fonte: OMC (2005).

Algumas das propostas de redução do apoio interno na Rodada Doha são as seguintes: o Brasil, como líder do G-20 e, esperando um resultado ambicioso nesse tema, propôs aos EUA e à UE um corte de $75 \%$ e $85 \%$, respectivamente, em seus subsídios totais distorcivos, soma das caixas amarela e azul. Por sua vez, a UE, após oferta inicial de 70\% de corte no apoio doméstico, aceita uma redução de $75 \%$ neles e pressiona os EUA para que eles concordem com uma redução de 65\% em seus subsídios totais distorcivos. Entretanto, os EUA, país com posicionamento 
mais defensivo nessa área, continuam a colocar que só podem aceitar um corte máximo de $53 \%$.

Segundo alguns analistas, é bastante provável que se chegue a um acordo na Rodada Doha no pilar de apoio doméstico, um dos mais difíceis da negociação, se os EUA melhorarem sua proposta, elevando os cortes ao nível de 65\%, e a UE mantiver os 75\% de redução em subsídios domésticos. Tal fato, mesmo representando um resultado aquém das demandas iniciais do G-20, representaria um avanço não desprezível para os interesses dos países em desenvolvimento com potencial de ganhos expressivos com a liberalização do setor agrícola. Contudo, vale frisar que os EUA têm insistido na abordagem do US\$ 1 por US\$1, isto é, só estariam prontos para abrir mão de medidas de apoio interno se ocorresse plena compensação em acesso a mercados na Europa e nos países em desenvolvimento. Destarte, dada à complexidade dos interesses em jogo, não se pode ter um posicionamento mais assertivo de como as negociações podem andar nos próximos meses.

Vale ressaltar que, além do foco nos cortes globais de apoio interno, muitos países em desenvolvimento, dentre eles o Brasil, têm especial interesses na criação de disciplinas claras e efetivas acerca da classificação nas caixas de subsídios, no intuito de evitar o chamado box shifting em detrimentos de seus interesses. A principal pendência, no momento, são as disciplinas mais rígidas para a caixa azul, que têm a oposição frontal dos EUA, tendo em vista que eles são contra disciplinas que venham obrigá-los a restringir os dispêndios com os pagamentos agrícolas contracíclicos. ${ }^{16}$ Em relação à caixa verde, subsídios que não distorcem, ou distorcem minimamente o comércio, a ideia defendida pelo G-20 é a de limitar o uso de pagamentos relacionados à proteção da renda em produtos específicos, por meio de pagamentos diretos desconectados de níveis de produção, buscando evitar que os programas distorcivos ao comércio agrícola internacional sejam alocados nessa caixa.

${ }^{16}$ É importante lembrar que os EUA já apresentaram uma proposta relativamente avançada de redução dos pagamentos na caixa azul dos $5 \%$ do valor da produção, apresentado no July 2004 Package, para 2,5\%. 
Ao mesmo tempo, os países do G-20 querem que haja mecanismos de supervisão e monitoramento mais eficazes, transparentes e impositivos sobre os subsídios domésticos e sobre a implementação do que for acordado na Rodada. Um dos principais problemas no sistema atual é a falta de transparência na notificação dos gastos com subsídios, sendo que alguns países permanecem por muitos anos sem notificá-los à OMC. Outro problema que deve ser resolvido é a falta de instrumentos que venham a obrigar os países-membros a debater e esclarecer suas políticas agrícolas no âmbito do Comitê de Agricultura da OMC.

Finalmente, no terceiro pilar das negociações agrícolas, relacionado ao acesso a mercado, os seguintes elementos estão sendo negociados: a fórmula de redução tarifária, picos e escalada tarifárias, tratamento de produtos sensíveis, salvaguardas especiais e produtos especiais. Até o presente momento, dada a dinâmica do processo negociador, a percepção que se tem é a de que dificilmente haverá uma liberalização ambiciosa do comércio agrícola na Rodada Doha.

Antes de nos atermos às negociações relacionadas à redução das tarifas que dificultam o comércio agrícola, vale aqui avaliarmos o perfil tarifário agrícola dos principais países participantes das negociações no intuito de melhor entender o desenrolar do processo negociador agrícola da Rodada Doha. Assim, apresentamos no Quadro 2, colocado na sequência, uma síntese dos perfis tarifários de países selecionados.

Quadro 2: Tarifas sobre o comércio agrícola em países selecionados (2004).

\begin{tabular}{|c|c|c|c|c|c|}
\cline { 2 - 6 } \multicolumn{1}{c|}{} & UE-15 & Japão & EUA & Índia & Brasil \\
\hline $\begin{array}{c}\text { Parte das linhas } \\
\text { tarifárias consolidadas }\end{array}$ & $100,0 \%$ & $99,5 \%$ & $100,0 \%$ & $97,5 \%$ & $100,0 \%$ \\
\hline $\begin{array}{c}\text { Parte das linhas } \\
\text { tarifárias duty free }\end{array}$ & $26,5 \%$ & $31,0 \%$ & $27,9 \%$ & $1,60 \%$ & $2,0 \%$ \\
\hline $\begin{array}{c}\text { Média simples da } \\
\text { tarifa consolidada pós- } \\
\text { Rodada Uruguai }\end{array}$ & $20,0 \%$ & $29,7 \%$ & $9,0 \%$ & $101,0 \%$ & $35,2 \%$ \\
\hline $\begin{array}{c}\text { Desvio padrão das } \\
\text { tarifas consolidadas }\end{array}$ & $22,1 \%$ & $12,6 \%$ & $5,5 \%$ & $51,0 \%$ & $10,1 \%$ \\
\hline
\end{tabular}




\begin{tabular}{|c|c|c|c|c|c|}
\cline { 2 - 6 } \multicolumn{1}{c|}{} & UE-15 & Japão & EUA & Índia & Brasil \\
\hline $\begin{array}{c}\text { Parte das linhas } \\
\text { tarifárias com tarifas } \\
\text { acima de 15\% }\end{array}$ & $33,9 \%$ & $17,5 \%$ & $2,6 \%$ & $99,4 \%$ & $96,4 \%$ \\
\hline $\begin{array}{c}\text { Parte das linhas } \\
\text { tarifárias com tarifas } \\
\text { acima de 100\% }\end{array}$ & $0,9 \%$ & $0,3 \%$ & $0,0 \%$ & $44,7 \%$ & $0,0 \%$ \\
\hline Tarifa média aplicada & $29,3 \%$ & $26,6 \%$ & $10,7 \%$ & $36,9 \%$ & $10,2 \%$ \\
\hline
\end{tabular}

Fonte: OMC (2005).

Como se pode vislumbrar, a UE-15 tem a maior tarifa média aplicada $(29,3 \%)$ e também o maior desvio padrão em suas linhas tarifárias $(22,1 \%)$ entre os países desenvolvidos, o que significa uma maior dispersão tarifária, denotando a probabilidade mais elevada de serem observados picos e escalada tarifárias contra importações agrícolas. No que concerne aos EUA, embora possua o menor desvio padrão da série (5,5\%) e tarifa média aplicada de 10,7\%, faz uso de mecanismos outros de proteção que não estão evidenciados no Quadro 2, porque nele se trabalha com tarifas comuns, deixando-se de lado o processo de tarificação. Ademais, vale destacar o perfil claramente protecionista da Índia em relação às tarifas impostas sobre o comércio agrícola. Apresentando um desvio padrão de 51\%, a Índia possui ainda $44,7 \%$ de suas linhas tarifárias com tarifas acima de $100 \%$ e uma tarifa média aplicada de 36,9\%, 39\% maior que a média tarifária aplicada no Japão $(26,6 \%)$ e $262 \%$ superior à do Brasil (10,2\%).

$\mathrm{Na}$ Conferência de Hong Kong, o pilar de acesso a mercado parece ter sofrido certo retrocesso, tendo em vista que permaneceu a completa indefinição relativamente à seleção e ao tratamento de acesso para produtos sensíveis, tema dos mais complexos nesse pilar. Ademais, cabe frisar que ficaram oficializados os instrumentos adicionais de proteção para os países em desenvolvimento como os produtos especiais e as salvaguardas especiais, atendendo às demandas protecionistas do G-120 (grupo de países em desenvolvimento com posicionamento mais defensivo na Rodada que é formado pela junção do G-33 com o G-90 e alguns países do G-20, dentre eles, Índia e China). Os produtos especiais escaparão dos cortes estabelecidos na Rodada e serão denominados pelos próprios países. Já as salvaguardas terão aplicação 
automática, seguindo gatilhos de quantidade e preço, sendo inclusive permitido o aumento de tarifas aplicadas além do patamar consolidado na OMC.

Em relação às negociações acerca dos cortes tarifários médios, as propostas atualmente na mesa de negociação são as seguintes: os EUA, com o apoio do Grupo de Cairns, apresentaram uma proposta na qual se sugere a realização de um corte médio de 75\% nas tarifas aplicadas em relação ao nível atual. Já a União Europeia, que apresenta uma sensibilidade maior nesse quesito, colocou em negociação a redução média das tarifas aplicadas em 39\%. Com uma proposta intermediária, o G-20 quer uma diminuição média de 54\% nas tarifas aplicadas. ${ }^{17}$ Vale lembrar que a complexidade das negociações de acesso a mercado em relação ao nível de desgravação tarifária a ser acordado envolve a escolha da fórmula como tal redução tarifária será efetivada, o que virá determinar o nível global médio de redução e a existência de tratamentos específicos.

No que tange aos produtos sensíveis, as negociações se complicam mais ainda, como pode ser observado a partir da abissal distância entre as proposições dos diversos grupos envolvidos. Por um lado, a atual proposta do G-20 é a de que a seleção dos produtos sensíveis não represente mais de $1 \%$ do total de linhas tarifárias. ${ }^{18} \mathrm{Tal}$ proposta vai de encontro com o desejo inicial do G-10 (grupo de países, chamado de "amigos da multifuncionalidade", no qual estão congregados Japão, Coreia, Noruega, Suíça e Israel, dentre outros) que defende que os sensíveis possam compor $15 \%$ das linhas tarifárias totais e da UE que quer $8 \%$ das linhas para os produtos sensíveis. Segundo estudo do Banco Mundial, basta que $2 \%$ das linhas tarifárias sejam consideradas como de produtos sensíveis para que os possíveis ganhos advindos da liberalização do comércio agrícolas sejam eliminados.

Ademais das discordâncias importantes sobre o percentual que deverá ser representado pelos produtos sensíveis no total das linhas tarifárias, resta ainda o

\footnotetext{
${ }^{17}$ Segundo a missão diplomática brasileira em Genebra, o Brasil, negociando sozinho, teria como proposta uma redução média nas tarifas aplicadas de $80 \%$.

${ }^{18} \mathrm{O}$ tratamento dado aos produtos sensíveis na proposta do G-20 é o de que o desvio máximo em relação à redução tarifária acordada na Rodada seja de $30 \%$. Soma-se a isso, a expansão da quota de importação para os produtos sensíveis de pelo menos $6 \%$.
} 
debate sobre a temporalidade ou não do regime especial para os produtos sensíveis. Logicamente, o G-10 e a UE defendem a ideia de que deve ser permitida a proteção de longo prazo para tais produtos em se mantendo os níveis atuais de produção. Por sua vez, o G-20, dentre outros, acredita na obviedade do caráter temporário do regime, visto como um mecanismo transitório de ajuste que tem como fim último a sua própria eliminação.

Assim, é fato que o pilar de acesso a mercado continua a ser o de maior complexidade negociadora e aquele com menor probabilidade de se conseguir um acordo focado numa liberalização mais ampla na Rodada Doha. De toda forma, resta observar como a dinâmica do processo negociador e dos interesses presentes no jogo diplomático serão materializados em propostas mais ou menos avançadas nos próximos meses, que poderão resultar no acordo final da Rodada.

Cabe aqui apresentar, como informação adicional, mas não menos importante, as negociações atuais acerca do comércio de algodão, que ganhou status diferenciado na OMC como iniciativa especial a partir do July 2004 Package. ${ }^{19}$ Após período de intensas negociações, acordou-se em Hong Kong o fim dos subsídios domésticos e das exportações direcionados ao setor algodoeiro já em 2006. Além disso, os países desenvolvidos também aceitaram dar acesso livre de gravames (tarifas e quotas) às exportações de algodão advindas dos países mais pobres. Tal decisão, embora de pequena abrangência, pode vir a ser um mecanismo de melhoria de renda para as populações pobres em diversos países africanos. Para o Brasil, a medida de maior importância está relacionada ao cortes nos subsídios totais, o que pode dar algum impulso às exportações brasileiras para mercados antes protegidos e subvencionados.

\footnotetext{
${ }^{19}$ Foi graças ao vitorioso contencioso que o Brasil realizou contra os EUA na OMC, juntamente com pressões de alguns países africanos (como Chade, Benin, Mali e Burkina Fasso), que se consegui dar atenção especial ao comércio de algodão na Rodada Doha.
} 


\section{Considerações finais}

As negociações nos três pilares agrícolas não têm avançado em conjunto. No pilar dos subsídios às exportações e medidas equivalentes, um progresso substancial, embora dentro de determinadas condições, pode ser visto; o que nos leva a acreditar na probabilidade elevada de se fechar um acordo final nos próximos meses. No que concerne ao apoio interno, segundo pilar das negociações, muito ainda resta a ser feito na tentativa de aproximação das propostas. Contudo, caso observemos sinalizações de ganhos em acesso a mercados por parte da Europa e dos países em desenvolvimento, é possível que os EUA cedam em relação aos cortes nos subsídios domésticos, o que levaria a um acordo final nesse pilar. Já no terceiro pilar, o do acesso a mercados, observa-se com certo temor as negociações que agora andam muito timidamente. Por envolver interesses protecionistas tanto de potências mundiais, como a UE, e de países em desenvolvimento, como a Índia, a temática toma contornos complexos e indefinidos.

As expectativas são de que não se consiga uma liberalização mais ambiciosa na Rodada Doha, o que poderia afetar diretamente, como colocado, as negociações no segundo pilar. Ademais, vale frisar que existe também certo paralelismo entre as negociações agrícolas com aquelas ligadas ao acesso ao Mercado de Produtos Não-Agrícolas (NAMA, na sigla em inglês), o que traz maior complexidade ao tratamento dos temas, tendo em vista que os países tendem a tentar contrabalancear "perdas" de um lado, com "ganhos" de outro, implicando num alongamento maior nas discussões.

Mais uma tentativa de se chegar a um acordo sobre o tema agrícola na Rodada Doha foi frustrada em julho de 2008, principalmente devido a divergências envolvendo, de um lado, os EUA e a UE, e de outro, as posições da China e da Índia sobre Special Safaguard Provision (SSP) para produtos agrícolas. Contudo, mesmo com a existência de um grande ceticismo acerca da possibilidade de sucesso efetivo na empreitada de se tentar finalizar a Rodada Doha nos próximos meses, cabe ressaltar que, no jogo político diplomático, as cartas a serem apresentadas podem sempre nos surpreender. Resta-nos, assim, observar com atenção como se dará o desenvolvimento do processo negociador nos próximos meses no que concerne à diplomacia comercial multilateral. 


\section{Abstract}

This work brings a historical analysis of the agriculture negotiations in the multilateral trading system from a Brazilian perspective, focusing on its importance to the economic development of developing countries. From an evolutionary perspective, the international context in which the multilateral trading system was created is presented in order to understand the power interaction that has led to the marginalization of agricultural themes in the GATT. Furthermore, the logics of conflict and negotiation about agricultural trade between developing countries are analyzed. At last, an analysis of the Doha Round of trade talks and its challenges and opportunities to the developing countries is presented, taking into account the importance of agricultural trade negotiations to the whole process.

Keywords: International trade. Agriculture. Development. WTO. Brazil

\section{Referências}

ABREU, Marcelo de P. Brazil, the GATT and the WTO: history and prospects. Rio de Janeiro: PUC, 1998. (Texto para discussão n 392). Disponível em: <www.pucrio.br>. Acesso em: 10 ago.2008.

ALMEIDA, Paulo Roberto de. Acordos minilaterais de integração e de liberalização do comércio: uma ameaça potencial ao sistema multilateral de comércio. In: . Negociações internacionais: mais do que produzir, é preciso saber negociar.

São Paulo: American Chamber, 2005. Disponível em: <www.pralmeida.org >. Acesso em: 28 jun. 2008.

ALMEIDA, Paulo Roberto de. Diplomacia comercial: de Bretton Woods e Havana à OMC. In: Relações internacionais e política externa do Brasil: história e sociologia da diplomacia brasileira. 2. ed. Porto Alegre: UFRGS, 2004. cap. 3.

BAUMANN, Renato et al. Economia internacional: teoria e experiência brasileira. Rio de Janeiro: Elsevier, 2004.

CHANG, Ha-Joon. Trade and industrial policy issues. In: CHANG, Ha-Joon (Org). Rethinking development economics. Londres: Anthem, 2003. cap. 12. 
CHANG, Ha-Joon; GRABEL, Ilene. Trade policy. In: Reclaiming development: an alternative policy manual. Londres: Zed Books, 2004. cap. 7.

DIAS, Viviane Ventura. O Brasil entre o poder da força e a força do poder. In: BAUMANN, Renato (Org). O Brasil e a economia global. Rio de Janeiro: Campus: SOBEET, 1996. cap. 4.

GONÇALVES, Reinaldo. Economia política internacional: fundamentos teóricos e as relações internacionais do Brasil. Rio de Janeiro: Elsevier, 2005.

GONÇALVES, Reinaldo. Globalização comercial. In: . O nó econômico. Rio de Janeiro: Record, 2003a. cap. 4.

GONÇALVES, Reinaldo. O Brasil e o comércio internacional: transformações e perspectivas. 2. ed. São Paulo: Contexto, 2003b.

GUIMARÃES, Feliciano de Sá. A rodada Uruguai do GATT (1986-1994) e a política externa brasileira: acordos assimétricos, coerção e coalizões. 2005. 195 f. Dissertação (Mestrado em Relações Internacionais do Programa San Tiago Dantas)- UNESP, UNICAMP, PUC-SP, Campinas, 2005.

JANK, Marcos S.; TACHINARDI, Maria H. Prioridades agrícolas na Rodada Doha em 2006: subsídios domésticos e acesso a produtos sensíveis. Revista Brasileira de Comércio Exterior, Rio de Janeiro, n. 86, p. 04-08, jan./mar. 2006.

JANK, Marcos S.; THORSTENSEN, Vera (Org.). O Brasil e os grandes temas do comércio internacional. São Paulo: Aduaneiras, 2005.

KHOR, Martin (Ed.). The multilateral trading system: a development perspective. New York: PNUD/TWN, 2001. Disponível em: <http://www.twnside.org.sg/pos. htm>. Acesso em: 28 set. 2008.

LAMPREIA, Luiz Filipe P. Resultados da rodada Uruguai: uma tentativa de síntese. Estudos Avançados, [S.l.], v. 9, n. 23, p. 247-260, 1995.

LIMA, Tatiana Macedo N. GATT/OMC: uma análise institucional. 2004. 97 f. Dissertação (Pós-graduação em Economia)- Faculdade de Economia, Administração e Contabilidade, Universidade de São Paulo, São Paulo, 2004.

MINISTERIAL DECLARATION. In: CONFERÊNCIA MINISTERIAL DA ORGANIZAÇÃO MUNDIAL DO COMÉRCIO, 4., 2001, Doha. Anais eletrônicos... 
Disponível em: <http://www.wto.org/english/thewto_e/minist_e/min01_e/ mindecl_e.htm>. Acesso em: 30 jul. 2008.

MRE. Carta de Genebra: informativo sobre a OMC e a rodada de Doha. Genebra, 2008. Disponível em: <www.mre.gov.br>. Acesso em: 30 set. 2008.

OATLEY, Thomas. International political economy: interests and institutions in the global economy. Londres: Longman, 2003.

OLIVEIRA, Ivan Tiago M. De Havana à Doha: o sistema multilateral de comércio em perspectiva histórica. Carta Internacional, São Paulo, v. 1, n. 2, p. 48-58, jul. 2006.

OMC. International trade statistics 2005. Genebra: OMC, 2005.

RÊGO, Elba C. L. Do GATT à OMC: o que mudou, como funciona e para onde caminha o sistema multilateral de comércio. Revista do BNDES, Rio de Janeiro, v. 3, n. 6, p. 3-22, dez. 1996.

RICUPERO, Rubens. Os Estados Unidos e o comércio mundial: protecionistas ou campeões do livre-comércio? Estudos Avançados, São Paulo, v. 16, n. 46, p. 07-18, set./dez. 2002.

RIOS, Sandra P. O impasse em Cancun e os impactos sobre a agenda brasileira. Revista Brasileira de Comércio Exterior, Rio de Janeiro, n. 77, p. 26-33, out./dez. 2003.

SATO, Eiiti. Mudanças estruturais no sistema internacional: a evolução do regime de comércio do fracasso da OIC à OMC. Brasília, 2001. Disponível em: <http:// www.cedep.ifch.ufrgs.br/Textos_Elet/pdf/DA\%20OIC\%20PARA \%20OMC\%20 2001.pdf>. Acesso em: 10 set. 2008.

SEITENFUS, Ricardo A. S. Manual das organizações internacionais. 4. ed. Porto Alegre: Livraria do Advogado, 2005.

VALLS, Lia. Histórico da Rodada Uruguai do GATT. Rio de Janeiro: UFRJ, 1997, 23 p. (Texto para discussão). Disponível em: <www.ie.ufrj.br $>$. Acesso em: 20 nov. 2008. 
